\title{
FORMULATION AND EVALUATION OF A CHITOSAN-PVA-GELLAN INSULIN IMPLANT
}

\author{
SATISH C. S. \\ aDepartment of Pharmaceutics, PES College of Pharmacy, 50 Feet Road, Hanumanthanagar, Bengaluru 570050, India \\ Email: satishcs@hotmail.com
}

Received: 13 Jan 2017, Revised and Accepted: 17 Apr 2017

\begin{abstract}
Objective: The purpose of this study was to ascertain the applicability of degradable materials for fabrication of an insulin release system.

Methods: Insulin implants were prepared by using poly (vinyl alcohol) (PVA), gellan and chitosan by solution casting method. The prepared implants were evaluated for swellability, content uniformity, potency and purity of insulin in implants, scanning electron microscopy studies, in vitro release studies, in vitro degradation studies using lysozyme, stability studies and circular dichroism spectroscopy.

Results: The swelling degree of the implants was found to be in the range of 1.07-1.56. The diffusion coefficient of water through the implant was found to depend on the calcium chloride $\left(\mathrm{CaCl}_{2}\right)$ concentration. The diffusion coefficient of insulin through the chitosan-PVA-gellan in the early stages was found to be in the range of $1.99 \times 10^{-5} \mathrm{~cm}^{2} / \mathrm{sec}$ to $5.24 \times 10^{-5} \mathrm{~cm}^{2} / \mathrm{sec}$ and at later stages in the range of $6.9 \times 10^{-6} \mathrm{~cm}^{2} / \mathrm{sec}^{2}$ to $1.10 \times 10^{-5}$ $\mathrm{cm}^{2} / \mathrm{sec}$. The weight of the implants was $48 \pm 0.58 \mathrm{mg}$. The insulin content in the implants was $9.86 \pm 0.10 \mathrm{mg}$. The potency of insulin extracted from the implants was $27.11 \pm 0.75 \mathrm{U} / \mathrm{mg}$ or $95.12 \pm 2.61 \%$ of the control insulin. The in vitro release studies showed that insulin was released completely in a period of 13-19 d depending on the composition of the implant. The increase in $\mathrm{CaCl}_{2}$ retarded the rate of insulin release whereas the increase in PVA content leads to the rapid release of insulin. The device was found to undergo significant weight loss due to enzyme mediated degradation.
\end{abstract}

Conclusion: These studies provide validity for the potential utility of chitosan-PVA-gellan implant systems for the delivery of insulin. The studies also demonstrate that insulin maintained its integrity within the implant system. Implants showed the complete release of insulin in $19 \mathrm{~d}$ and the release of insulin from the implants depended on the amount of $\mathrm{CaCl}_{2}$.

Keywords: Insulin, Degradation, Diffusion, Gellan, Chitosan

(C) 2017 The Authors. Published by Innovare Academic Sciences Pvt Ltd. This is an open access article under the CC BY license (http://creativecommons.org/licenses/by/4.0/) DOI: http://dx.doi.org/10.22159/ijap.2017v9i3.17074

\section{INTRODUCTION}

Diabetes mellitus refers to a group of metabolic diseases characterised by chronic hyperglycemia, due to defects in insulin secretion. The treatment of diabetes by insulin injection provides only a poor approximation of normal glucose homoeostasis, especially for insulindependent diabetes where blood glucose concentrations vary widely despite insulin therapy $[1,2]$. This is because the pharmacokinetics of insulin following subcutaneous injection does not match the profiles of physiological insulin secretion [3, 4]. Moreover, subcutaneous injections result in localized insulin deposits that lead to local hypertrophy and fat deposits under the skin. Together these disadvantages lead to suboptimal pharmacodynamics properties of the applied insulin, which does not allow mimicking the complex physiological insulin secretion pattern [5].

Polymeric implants are one of the promising devices for protein drug delivery. Some polymeric matrices can protect drugs from physiological conditions that could degrade the proteins. Therefore, a lot of research is ongoing to identify appropriate polymer systems to formulate ideal protein drug delivery systems that would allow ease of incorporation of protein drugs without affecting their bioactivity, deliver them at the desired rate and exhibit biocompatibility when in contact with the tissue [6]. Gellan is an anionic polysaccharide of microbial origin, which is capable of forming a three-dimensional network by complexation with cations and hydrogen bonding with water. The apparent viscosity of gellan gum dispersions can be markedly increased by increasing both $\mathrm{pH}$ and cation concentration [7]. Furthermore, its ingestion has never produced reported adverse dietary, physiological or toxic effects in animals and humans. These properties make this polysaccharide suitable for several commercial applications, such as in the food industry and in drug delivery [8]. While gellan gum has never been used to deliver biologically active macromolecules, it has some potential for this application. The ioninduced cross-linking property of gellan avoids the presence of initiator or organic cross-linker that can be toxic to the protein activity if not removed from the device. The preparation also does not need to involve organic solvents and/or high temperatures that could denature the protein. Polyvinyl alcohol (PVA) is one of the hydrogels often used in biomedical applications [9]. It is a water-soluble synthetic polymer with excellent film forming, emulsifying and adhesive properties. Chitosan forms a polyionic complex with gellan and this property was used in the current work to prepare an insulin implant of chitosan-PVA-gellan for maintenance of prolonged therapeutic levels of insulin.

The objective of this investigation was to develop a chitosan-PVAgellan implant device as an implant for insulin delivery. The procedure for the preparation of chitosan-PVA-gellan implant was optimized. The swelling index and in vitro release characteristics for drug delivery were investigated.

\section{MATERIALS AND METHODS}

\section{Materials}

Gellan, polyvinyl alcohol (average molecular weight range 1,20,000$1,80,000$ and degree of hydrolysis 99\%), Chitosan (medium molecular weight, $75-85 \%$ deacetylated), insulin (porcine pancreas) were purchased from Sigma, St. Louis, MO, USA. Lysozyme (HiMedia $50,000 \mathrm{U} / \mathrm{mg})$, Calcium chloride $\left(\mathrm{CaCl}_{2}\right)$, potassium dihydrogen phosphate, sodium hydroxide and sodium chloride were obtained from SISCO Scientific Laboratories, Mumbai India.

\section{Preparation of chitosan-PVA-gellan insulin implant}

The compositions of various formulations are given in table 1 . A $0.5 \% \mathrm{w} / \mathrm{v}$ chitosan solution in $0.2 \mathrm{M}$ acetic acid was poured into a glass mold (Area $28.3 \mathrm{~cm}^{2}$ ) and dried at $25{ }^{\circ} \mathrm{C}$ under vacuum for 48 h. PVA was dissolved in water by heating to $90{ }^{\circ} \mathrm{C}$, to which gellan and glycerin $(2 \% \mathrm{v} / \mathrm{v})$ were added and stirred until a clear solution was obtained. To this solution, insulin dissolved in small volume of $0.1 \mathrm{~N} \mathrm{HCl}$ and diluted with $\mathrm{pH} 7.4$ phosphate buffered saline (PBS) was added at $25{ }^{\circ} \mathrm{C}$ and stirred gently [9]. The solution was then poured over the chitosan film in a glass mould and dried at $25^{\circ} \mathrm{C}$ under vacuum for $24 \mathrm{~h}$. Over this layer $10 \mathrm{ml}$ of $0.5 \%$, w/v of chitosan was poured and was allowed to dry at $25^{\circ} \mathrm{C}$ under vacuum. The dry formulations were cut into $10 \mathrm{~mm}$ circular discs. 
Table 1: The composition of various formulations

\begin{tabular}{llcc}
\hline Ingredients & F-I & F-II & F-III \\
\hline Gellan (\% w/v) & 1 & 1 & 1 \\
Poly(vinyl alcohol) (\% w/v) & 3 & 3 & 3 \\
Glycerin (mL) & 3 & 6 & 3 \\
CaCl$_{2}(\% \mathrm{w} / \mathrm{v})$ & 0.05 & 0.1 & 0.05 \\
Distilled water (mL) & 20 & 20 & 20.1 \\
\hline
\end{tabular}

\section{Content uniformity, potency and purity of insulin in implants}

Content uniformity and insulin potency in the implants was determined by an RP-HPLC method (Shimadzu LC 10 AD, Japan). The implants were reduced to small pieces and placed in $20 \mathrm{ml}$ of $0.05 \mathrm{~N} \mathrm{HCl}$ for $24 \mathrm{~h}$ and filtered using Whatman filter paper. From this $0.1 \mathrm{ml}$ was pipetted out into a $10 \mathrm{ml}$ standard volumetric flask and made up to the volume with $0.05 \mathrm{~N} \mathrm{HCl}$ and assayed for drug content by reversed-phase high-performance liquid chromategraphy method (RP-HPLC). The RP-HPLC consisted of the C-18 column; the mobile phase was $0.2 \mathrm{M}$ sodium sulphate $(\mathrm{pH} 2.3)$ and acetonitrile in the ratio of $74: 26$. The flow rate was $1 \mathrm{ml} / \mathrm{min}$ and the insulin was detected using UV detector at $214 \mathrm{~nm}$ [10].

The potency of insulin was calculated from the relationship:

$$
\mathrm{Cu}=\frac{\mathrm{C}_{\mathrm{S}} \mathrm{R}_{\mathrm{U}}}{\mathrm{R}_{\mathrm{S}}}
$$

Where $C_{u}$ is the potency of the unknown, $C_{s}$ : is standard potency, $\mathrm{R}_{\mathrm{u}}$ : peak area of unknown and $\mathrm{R}_{\mathrm{s}}$ : peak area of the standard [11].

\section{Swelling studies}

Implants were placed in a glass beaker containing $50 \mathrm{ml}$ of phosphate buffered saline (PBS, $\mathrm{pH}$ 7.4) and the beakers were placed in a shaking incubator at $37{ }^{\circ} \mathrm{C}$ and $100 \mathrm{rpm}$. The implants were weighed periodically throughout the experiment. The swelling process was characterised by the swollen weight ratio $\left(q=W_{s} / W_{d}\right)$, where $W_{s}$ is the weight of the swollen implant and $W_{d}$ is the weight of the initial dry implant. The swelling studies were carried out in triplicate. The Berens-Hopfenberg equation [12] was fitted to the data obtained from the swelling studies.

$$
\frac{M_{t}}{M_{\infty}}=\left\{1-A \exp \left(K_{2} t\right)\right\}(1)
$$

where $\mathrm{A}$ and $\mathrm{k}_{2}$ are constants calculated from the slopes and intercepts of the plot of $\log \left(1-\mathrm{M}_{t} / \mathrm{M}_{\infty}\right)$ versus time $t$ at times later than those corresponding to $\mathrm{M}_{\mathrm{t}} / \mathrm{M}_{\infty}=0.6$. The equation $\mathrm{M}_{\mathrm{t}} / \mathrm{M}_{\infty}=\mathrm{kt}^{\mathrm{n}}$ adequately describing a major portion of the swelling behaviour fails to give an accurate analysis above $\mathrm{M}_{t} / \mathrm{M}_{\infty}=0.6$. To obtain a better model after $60 \%$, we have used Berens-Hopfenberg equation.

\section{Scanning electron microscopy studies}

The surface morphology of dried implants was determined using a scanning electron microscope (JEOL 6320). The implant samples were mounted on a base plate and coated with gold using a vapour deposition technique. The surface was then scanned at magnifications of $500 \times$ and $1000 \times$.

\section{In vitro release studies}

The implant was placed in $100 \mathrm{ml}$ glass beaker containing $50 \mathrm{ml}$ of PBS (pH 7.4). The beaker was placed in a shaking incubator at $37^{\circ} \mathrm{C}$ and $100 \mathrm{rpm}$. The samples were withdrawn every $24 \mathrm{~h}$ and the insulin concentration was determined using RP-HPLC. The in vitro release studies were carried out until the complete release of insulin was observed.

\section{Mathematical analysis of water uptake and drug release}

Analysis of the swelling behaviour of implants in PBS at pH 7.4 was carried out using the equation.

$$
\frac{M_{t}}{M_{\infty}}=1-\frac{8}{\pi^{2}} \exp \frac{\left(-\pi^{2} D t\right)}{4 \delta^{2}} \text { for } 0.4<M t / M \infty<1 \text { (2) }
$$

Where D is the water diffusion coefficient, $\delta$ the half thickness of the implant, $\mathrm{M}_{\mathrm{t}}$ the amount of water uptake at the time, $\mathrm{t}$ and $\mathrm{M}_{\infty}$ is the water uptake at equilibrium [13]. Diffusion coefficients of insulin through the implants were calculated with Eqs. 2 and 3:

$$
\frac{M_{t}}{M_{\infty}}=4\left(\sqrt{\frac{D t}{\pi \delta^{2}}}\right) \text { for } 0.4<M t / M \infty<1
$$

Where $\mathrm{D}$ is the insulin diffusion coefficient, $\delta$ the half thickness of the implant, $\mathrm{M}_{\mathrm{t}}$ the amount of insulin released at the time, $\mathrm{t}$ and $\mathrm{M}_{\infty}$ is the amount of insulin in the implant. Equation 3 was used to calculate the diffusion coefficient of insulin at early stages when the fraction of insulin released $\left(\mathrm{M}_{\mathrm{t}} / \mathrm{M}_{\infty}\right)$ was less than 0.6 and for later stages equation 2 was used when the fraction of insulin released $\left(\mathrm{M}_{\mathrm{t}} / \mathrm{M}_{\infty}\right)$ was greater than 0.6. This is because plotting with equations 2 and 3 fits the experimental data well until $\mathrm{M}_{\mathrm{t}} / \mathrm{M}_{\infty}<0.6$.

\section{Enzyme-mediated degradation studies}

The implants were placed in $10 \mathrm{ml}$ phosphate buffer $\left(\mathrm{pH} 7.4,37^{\circ} \mathrm{C}\right)$ containing lysozyme enzyme $(1 \mathrm{mg} / \mathrm{ml})$. The PBS was changed for all the samples every day. Implants were taken out at 7, 14, 21 and $28 \mathrm{~d}$, washed with distilled water and air-dried for $72 \mathrm{~h}$. The resulting dry weights were recorded. The mass loss of the samples was determined by gravimetry.

\section{Stability studies}

The stability protocol was based on the International Conference on Harmonisation (ICH) ' $\mathrm{Q} 1 \mathrm{~A}\left(\mathrm{R}_{2}\right)^{\prime}$ guidelines. The implants were stored at $25^{\circ} \pm 2{ }^{\circ} \mathrm{C}$ and $60 \pm 5 \% \mathrm{RH}$ for and at $5^{\circ} \pm 3^{\circ} \mathrm{C}$ which is the accelerated storage temperature and long term storage temperatures respectively, for products intended to be refrigerated. Stability studies were performed for e formulation F2. The stability testing of samples was carried out at 0, 60, 120 and $180 \mathrm{~d}$ under long-term storage conditions. For accelerated conditions, the samples were assayed every $10 \mathrm{~d}$ for $30 \mathrm{~d}$.

\section{Circular dichroism spectroscopy}

Circular dichroism (CD) spectra were obtained with a Jasco J-810 spectropolarimeter (Japan) equipped with a Pelltier temperature controller. Spectra were collected at $20^{\circ} \mathrm{C}$ using a $0.1 \mathrm{~cm}$ cell over the wavelength range of $200-270 \mathrm{~nm}$. A resolution of $0.1 \mathrm{~nm}$ and scanning speed of $10 \mathrm{~nm} / \mathrm{min}$ with a $2 \mathrm{~s}$ response time were employed. Each spectrum obtained represents an average of three consecutive scans. Noise reduction, blank buffer subtraction, and data analysis were performed using standard analysis and temperature/wavelength analysis programs (Jasco). Secondary structure content was estimated employing CDPro software with data in the range of 200-240 nm using the basis 4 and 7 programs for input data. Loaded implants containing insulin were dialyzed against water at $4{ }^{\circ} \mathrm{C}$ for $24 \mathrm{~h}$ before analysis by CD. Standard insulin solutions were prepared at $0.1 \mathrm{mg} / \mathrm{ml}$ in $10 \mathrm{mmol}$ PBS.

\section{RESULTS AND DISCUSSION}

\section{Content uniformity, potency and purity of insulin in implants}

The disc implants were $48 \pm 0.58 \mathrm{mg}$ and had a thickness $851 \pm 8.9$ $\mu \mathrm{m}$. The insulin content in the implants was $9.86 \pm 0.10 \mathrm{mg}$. The potency of insulin extracted from the implants was $27.11 \pm 0.75$ $\mathrm{U} / \mathrm{mg}$ or $95.12 \pm 2.61 \%$ of the control insulin. There was no significant difference $(\mathrm{p}<0.001)$ in potency or purity of the insulin extracted from implants compared to that of standard insulin. In addition, after storage at $2-8{ }^{\circ} \mathrm{C}$ for $6 \mathrm{mo}$, insulin in the implants manifested the same potency and purity as the initial preparation. 


\section{Swelling studies}

Primarily three mechanisms could be responsible for the release of drugs from the hydrogels: swelling, diffusion and degradation. Upon exposure to an aqueous media, first, the polymer swells due to the uptake of the water. The rate of water uptake by the implant depends on the hydrophobicity of the polymer. Second, when the implant swells, the encapsulated drug is released by diffusion through the pores formed due to swelling. The third mechanism, which involves degradation of the polymer matrix, would occur under in vivo conditions as a result of enzyme activity.

The effect of crosslinking agents on the swell ability of the polymer could be demonstrated by the diffusion coefficient of water in the implant system. Moreover, the rate of drug delivery from an implant also depends on the rate of diffusion of the waterfront into the device. It is known that the greater the molecular size/weight of the drug, the greater is the sensitivity of the diffusion coefficient to changes in crosslink density. Insulin is regarded as a macromolecular peptide whose release from the implant apparently depends on the diffusion coefficient of water in the device as well as on the swellability of the polymer.

The swelling degree of the implants was found to be in the range of 1.07-1.56. The Berens-Hopfenberg differential equation $\frac{M_{t}}{M_{\infty}}=\left\{1-A \exp \left(K_{2} t\right)\right\}$ was fitted to the data obtained from the swelling studies to assess the overall kinetics governing the swelling.
In this equation, $\mathrm{M}_{t}$ is the swelling at time $t$ and $\mathrm{M}_{\infty}$ is the equilibrium swelling. In this studies, the constants $\mathrm{A}$ and $\mathrm{k}_{2}$ were calculated from the slopes and intercepts of the plot of $\log (1-$ $M_{t} / M_{\infty}$ ) versus time $t$ at times later than those corresponding to $\mathrm{M}_{\mathrm{t}} / \mathrm{M}_{\infty}=0.6$. The calculated values of $\mathrm{A}$ and $\mathrm{k}_{2}$ are listed in table 2 . The values of A were in the range of 0.17-0.43 indicating Fickian diffusion. The diffusion coefficient for water transport was calculated by plotting $\log \left[\pi^{2} / 8\left(1-\mathrm{M}_{\mathrm{t}} / \mathrm{M}_{\infty}\right)\right]$ versus $\mathrm{t}$ for $0.4<\mathrm{M}_{\mathrm{t}} / \mathrm{M}_{\infty}<1$ (Eq. 2). The slope of the plot was $\pi^{2} \mathrm{D} / 2.303 \times 4 \delta^{2}$ from which the diffusion coefficient D was calculated (table 2). The diffusion coefficient of water through the implant was found to depend on the $\mathrm{CaCl}_{2}$ concentration.

The maximum diffusion coefficient was observed with implants prepared with a $\mathrm{CaCl}_{2}$ concentration of $0.05 \% \mathrm{w} / \mathrm{v}$. When the cross linker concentration was increased from $0.05 \% \mathrm{w} / \mathrm{v}$ (F1) to $0.1 \%$ $\mathrm{w} / \mathrm{v}$ (F2) the diffusion coefficient of water through the implant decreased from $2.08 \times 10^{-4}$ to $1.73 \times 10^{-4} \mathrm{~cm}^{2} / \mathrm{sec}$ and from $2.28 \times 10^{-6}$ to $2.18 \times 10^{-6} \mathrm{~cm}^{2} / \mathrm{sec}$ for F3 and F4, respectively. This may be explained by the fact that on increasing the crosslinker content there is a prominent decrease in the free volumes available between the chains of the macromolecular network and thus the swelling of implant decreases. The crosslink density of hydrogels provides a restricted aqueous environment for diffusional migration of the peptide, by controlling both the degree of hydration and the permeability of hydrogels to protein [14].

Table 2: Parameters $A, k_{2}$ and diffusion coefficient of water from swelling studies

\begin{tabular}{lllll}
\hline Formulations & A & $\mathbf{k}_{\mathbf{2}} \times \mathbf{1 0} \mathbf{0}^{-\mathbf{3}} \mathbf{( \mathbf { m i n } ^ { - 1 } )}$ & $\mathbf{R}^{\mathbf{2}}$ & $\mathbf{D} \mathbf{( \mathbf { c m } ^ { 2 } / \mathbf { s e c } )}$ \\
\hline F1 & 0.25 & 3.1 & 0.992 & $2.08 \times 10^{-4}$ \\
F2 & 0.17 & 2.6 & 0.973 & $1.73 \times 10^{-4}$ \\
F3 & 0.43 & 5.3 & 0.986 & $2.28 \times 10^{-6}$ \\
F4 & 0.28 & 6.5 & 0.991 & $2.18 \times 10^{-6}$ \\
\hline
\end{tabular}

$(n=3)$ mean $\pm S D$

\section{Scanning electron microscopy studies}

The scanning electron microscopy studies of the PVA/gellan implants (fig. 1 and 2) clearly showed a difference in the microstructure of the swollen and dry state of the cross section of the implant. This provides structural proof for the hypotheses we made regarding the release of insulin from the implant systems due to swelling of the polymer.

\section{In vitro release studies}

The formulation F1 showed the complete release of insulin in $16 \mathrm{~d}$ while for F2, F3 and F4 complete release of insulin were seen in 19, 13 and $15 \mathrm{~d}$ respectively. Obviously, this infers that the release depends on the PVA content and $\mathrm{CaCl} 2$ concentration in the formulation. The increase in $\mathrm{CaCl} 2$ retarded the rate of insulin release whereas the increase in PVA content leads to rapid release of insulin. The in vitro release of the various formulations is shown in the fig. 3 . The fraction of insulin released $(\mathrm{Mt} / \mathrm{M} \infty)$ less than 0.6 was fitted to the equation $\mathrm{Mt} / \mathrm{M} \infty=\mathrm{ktn}$, where $\mathrm{Mt}$ is the insulin released at time $\mathrm{t}, \mathrm{M}_{\infty}$ is the maximum insulin released, $\mathrm{k}$ is the characteristic constant of the polymer, and $\mathrm{n}$ is the characteristic exponent describing the penetration mechanism. For planar geometry, a value of $n=0.5$ indicates a Fickian diffusion mechanism, $0.5<\mathrm{n}<1.0$ indicates nonFickian or anomalous transport, and $n=1$ implies case II (relaxation controlled) transport. The constants $\mathrm{n}$ and $\mathrm{k}$ were calculated from the slope and intercepts of the plots of $\log (\mathrm{Mt} / \mathrm{M} \infty)$ versus $\log \mathrm{t}$ respectively. The calculated value of $n$ was $0.86-0.89$, which indicated that the release of insulin followed non-Fickian or anomalous transport. This suggests that the release of insulin from the implant was controlled by swelling of the matrix due to water penetration into the implant.

The diffusion coefficient of insulin (molecular weight 5900, hydrodynamic radius $16 \mathrm{~A}^{\circ}$ ) was calculated using Eqs. 2 and 3 (table 3). The diffusion coefficient of insulin decreased when the concentration of $\mathrm{CaCl}_{2}$ increased due to an increase in the crosslink density, which compacts the network. It is likely that the increase in the compactness restricts the mobility of the network chains (chain relaxation) and impedes diffusion of insulin from the implant.

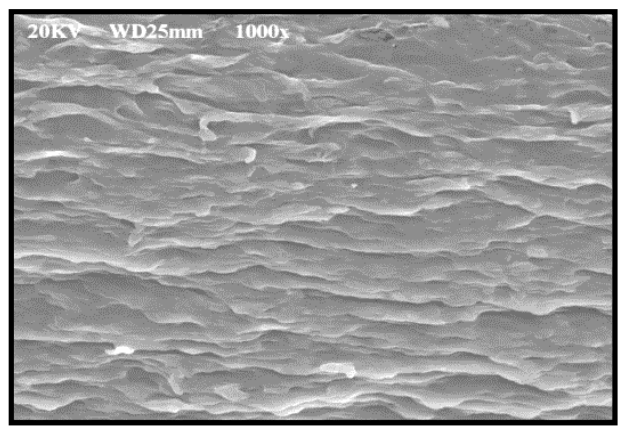

Fig. 1: SEM pictures of cross-section of implant (F2) before swelling

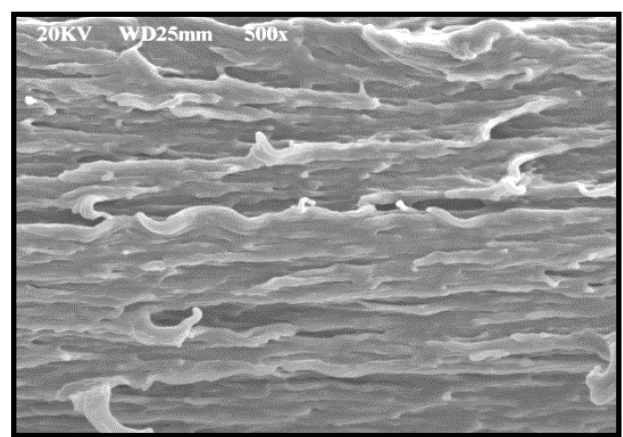

Fig. 2: SEM pictures of cross-section of implant after swelling (F2) in a buffer medium over a period of $240 \mathrm{~min}$

Table 3: Diffusion coefficients of insulin through the implant 


\begin{tabular}{lll}
\hline Formulations & Diffusion coefficient $\left(\times \mathbf{1 0}^{-\mathbf{5}} \mathbf{c m}^{\mathbf{2}} \mathbf{\mathbf { s e c }}\right)$ & \\
\cline { 2 - 3 } & Early stages & Later stages \\
\hline F1 & 6.65 & 0.92 \\
F2 & 3.33 & 0.69 \\
F3 & 8.73 & 1.10 \\
F4 & 7.85 & 0.77 \\
\hline
\end{tabular}

$(\mathrm{n}=3)$ mean $\pm \mathrm{SD}$

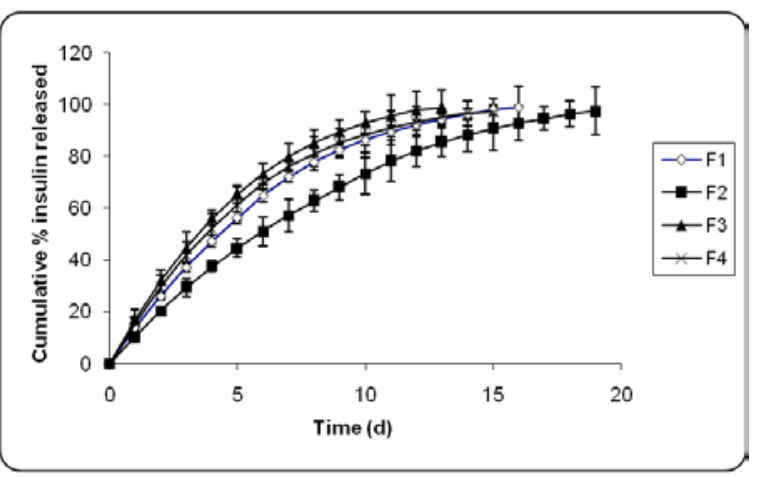

Fig. 3: In vitro release studies of insulin implants in PBS (7.4) at $37^{\circ} \mathrm{C}, \mathrm{n}=3$, Data presented as mean $\pm S D$

\section{Enzyme-mediated degradation studies}

It is known that chitosans with block structures and lower degrees of deacetylation $(<75 \%)$ are more readily degraded due to the presence of blocks of glucosamine moieties containing acetyl groups that serve as a substrate for lysozyme. In the present study, we used chitosan $(75-85 \%$ deacetylated) that has been shown to degrade in vivo in about $6 \mathrm{mo}$ [15].

The in vitro degradation studies showed that there was a significant weight loss of the implants when placed in phosphate buffer solution $\mathrm{pH} 7.4$ containing lysozyme indicating the degradation of the implants. The degradation studies were carried out for $4 \mathrm{w}$ and the $\%$ weight loss of the implants was found to be $20.8 \pm 2.0$ (fig. 4).

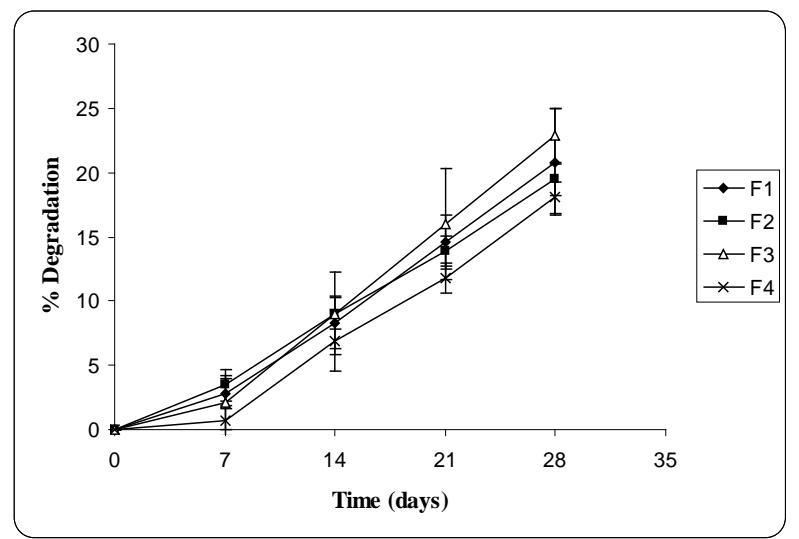

Fig. 4: Degradation studies of the implants F1, F2, F3 and F4, $n=3$, Data presented as mean $\pm S D$

\section{Stability studies}

Observations under long-term storage conditions and accelerated conditions are shown in the fig. 5 and 6 . The insulin content in the formulation in long-term storage conditions and accelerated storage conditions along with 95\% confidence limits were plotted (sigmaplot ${ }^{\circledR}$ version 9.0). When the implants were stored under long-term storage conditions the insulin content in formulation F2 was found to be $9.47 \pm 0.06 \mathrm{mg}$ ( $94.7 \%$ of the initial content) after six mo. Under accelerated conditions, the insulin content was $7.50 \pm 0.23$ $\mathrm{mg}(75 \%$ of the initial content). These results suggest that at any time (either during transit or storage) the insulin implants should be stored at refrigerator temperatures.

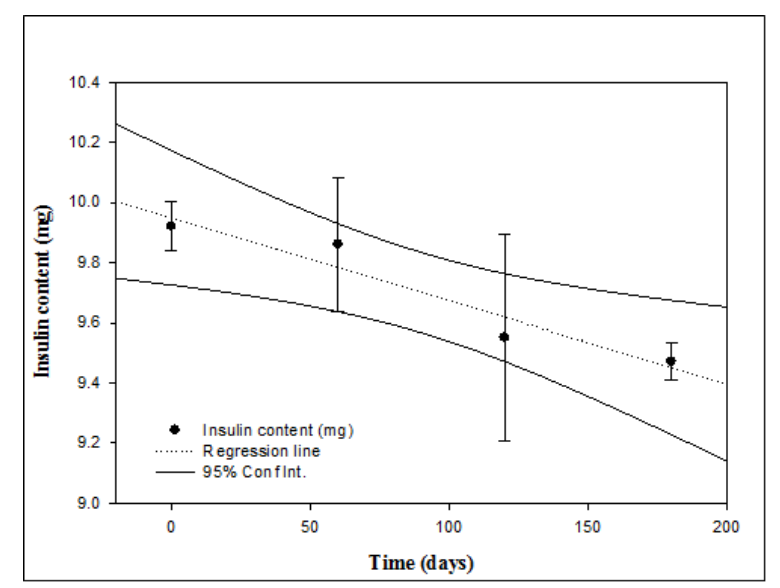

Fig. 5: Insulin content in the implants (F2) when stored at $5^{\circ} \pm 3$ ${ }^{\circ} \mathrm{C}$ for $180 \mathrm{~d}, \mathrm{n}=3$, Data presented as mean $\pm \mathrm{SD}$

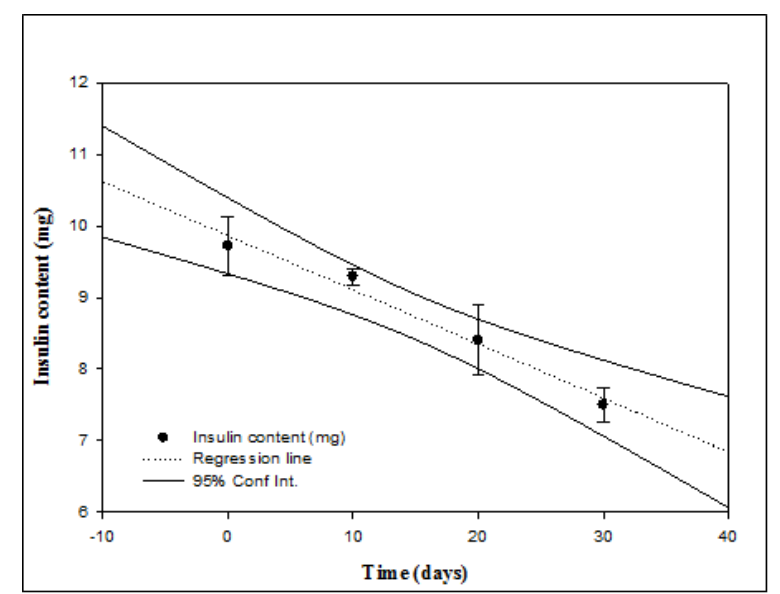

Fig. 6: Insulin content in the implants (F2) when stored at $25 \pm 2$ ${ }^{\circ} \mathrm{C}$ and $65 \% \mathrm{RH} \pm 5 \% \mathrm{RH}$ for $30 \mathrm{~d} . \mathrm{n}=3$, Data presented as mean \pm SD

\section{Circular dichroism spectroscopy}

The CD spectra of control insulin and the insulin extracted from the implant (F2) are shown in fig. 7.

Compared with the CD spectrum of control insulin, no significant change was observed in that of the insulin extracted from the implant in the PBS solution, indicating that the conformation of insulin remained unchanged in the implants. 


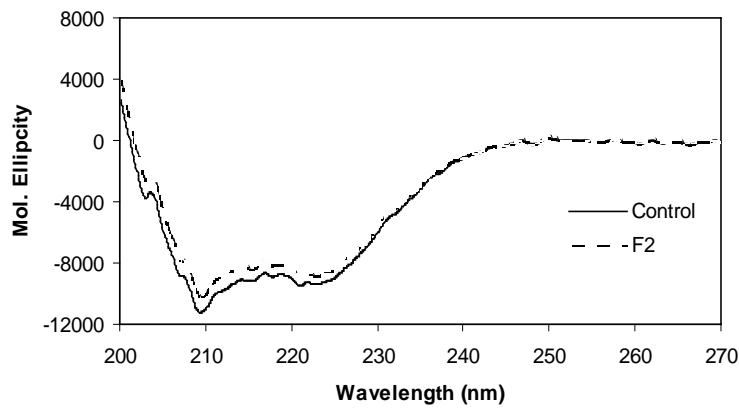

Fig. 7: The CD spectra

\section{CONCLUSION}

These studies provide validity for the potential utility of chitosanPVA-gellan implant systems for the delivery of insulin. The studies also demonstrate that insulin maintained its integrity within the implant system. Implants showed the complete release of insulin in $19 \mathrm{~d}$ and the release of insulin from the implants depended on the amount of $\mathrm{CaCl}_{2}$. Further investigations to prolong the release of insulin over longer durations will be undertaken.

\section{ACKNOWLEDGEMENT}

The authors wish to thank AICTE, New Delhi for the funding received through MODROBS

\section{CONFLICTS OF INTERESTS}

Declare none

\section{REFERENCES}

1. Jain R, Jain P, Jain P. A review on treatment and prevention of diabetes mellitus. Int J Curr Pharm Res 2016;8:16-8.

2. Omar MS, San KL. Diabetes knowledge and medication adherence among geriatric patient with type 2 diabetes mellitus. Int J Pharm Pharm Sci 2014;6:103-6.
3. Brange J, Vølund A. Insulin analogues with improved pharmacokinetic profiles. Adv Drug Delivery Rev 1999;35:307-35.

4. Albin G, Horbett TA, Ratner BD. Glucose sensitive membranes for controlled delivery of insulin: insulin transport studies. J Controlled Release 1985;2:153-64.

5. Siegel RA, Firestone BA. Mechanochemical approaches to selfregulation insulin pump design. J Controlled Release 1990;11:181-92.

6. Patil P, Chavanke D, Wagh M. A review on ionotropic gelation method: a novel approach for controlled gastro retentive gelispheres. Int J Pharm Pharm Sci 2012;4:27-32.

7. Deasy PB, Quigley J. Rheological evaluation of deacetylated gellan gum (gelrite) for pharmaceutical use. Int J Pharm 1991;73:117-23.

8. Santucci E, Alhaique F, Carafa M, Coviello T, Murtas E, Riccieri FM. Gellan for the formulation of sustained delivery beads. J Controlled Release 1996;42:157-64.

9. Lowman AM, Morishita M, Kajita M, Nagai T, Peppas NA. Oral delivery of insulin using pH-responsive complexation gel. J Pharm Sci 1999;88:933-7.

10. Oliva JB, Llabrés M. Influence of temperature and shaking on the stability of insulin preparations: degradation kinetics. Int ] Pharm 1996;143:163-70.

11. Tiyaboonchai W, Woiszwillo J, Sims RC, Middaugh CR. Insulincontaining polyethyleneimine-dextran sulfate nanoparticles. Int J Pharm 2003;255:139-51.

12. Kim B, Flamme KL, Peppas NA. Dynamic swelling behaviour of $\mathrm{pH}$-sensitive anionic hydrogels used for protein delivery. J Appl Poly Sci 2003;89:1606-13.

13. Brazel CS, Peppas NA. Mechanisms of solute and drug transport in relaxing, swellable, hydrophilic glassy polymers. Polymer 1990;40:3383-98.

14. Pitt CG. The controlled parenteral delivery of polypeptides and proteins. Int J Pharm 1990;59:173-96.

15. Tomihata K, Ikada Y. In vitro and in vivo degradation of films of chitin and its deacetylated derivatives. Biomaterials 1997; 18:567-75.

\section{How to cite this article}

- $\quad$ Satish CS. Formulation and evaluation of a chitosan-pva-gellan insulin implant. Int J Appl Pharm 2017;9(3):37-41. 